\title{
Erratum
}

\section{Integrated Reservoir Characterization and Petrophysical Analysis of Cretaceous Sands in Lower Indus Basin, Pakistan}

Perveiz Khalid*, Muhammad Irfan Ehsan, Sohail Akram, Zia Ud Din and Shahid Ghazi Institute of Geology, University of the Punjab 54590 Lahore, Pakistan

E-mail: perveiz.geo@pu.edu.pk*; Irfan_opq@yahoo.com; Sohail.geo@pu.edu.pk; ziauddinpu@yahoo.com; ghazigeo6@gmail.com

In the above published article in October 2018 issue of the Journal of the Geological Society of India (v.92, pp.465-470). On page 466, Figure 1 is incorrect and should be replaced by the figure given below

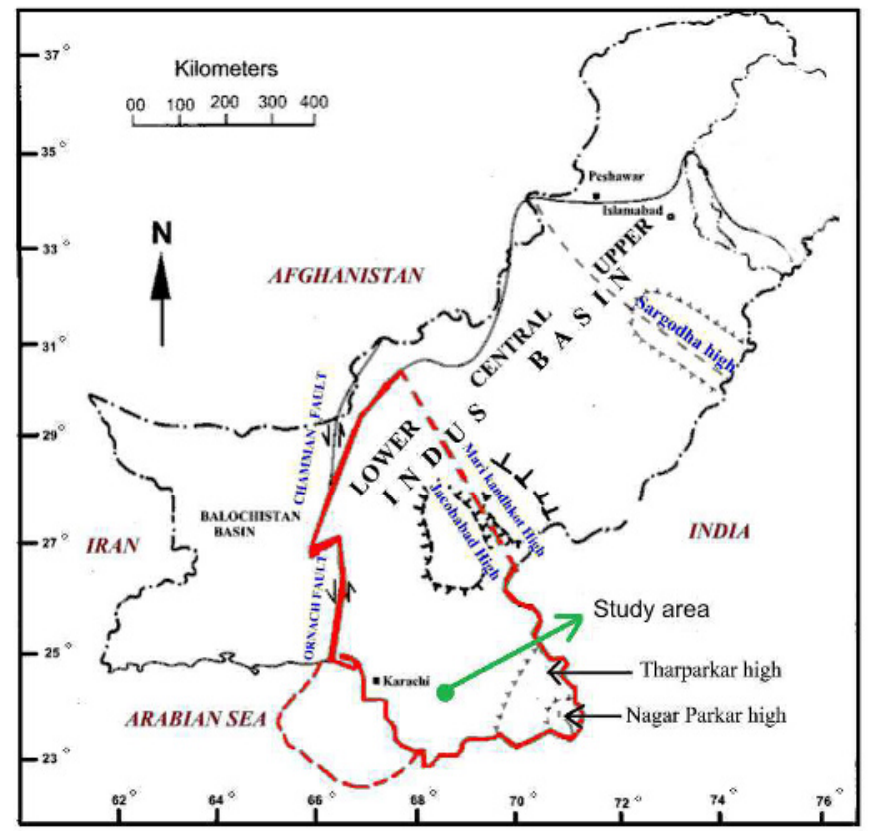

Fig.1. Tectonic map of Pakistan alongwith location of the study area. The arrow represents the location of the study area. 